\title{
The Shifting Sands of Music Leadership: Searching for Disciplinary Space in a Research-led University
}

\section{Chatradari 'Chats' Devroop}

\section{Abstract}

From the perspective of an arts-based discipline in need of curricular transformation, this paper examines certain fragilities within the university systems and calls for a transformational style of leadership. Recent events in higher education in South Africa have brought to light the crisis in leadership at its public universities, with critical focus on curriculum leadership. While universities may conceive of themselves as being under attack, with their legitimacy, traditions and values being called into question, current student opinion is that the issue of leadership in universities fails to be sufficiently transparent when compared to the public or private sectors. This research is located within an autoethnographic context and highlights the experience and challenges of an academic leader in the arts, and specifically, the music discipline. The experiential data affords insight into problems existing between leadership, management and more especially the academic leadership of the discipline. While arguing for a different role for curriculum leadership within the contemporary university, this paper goes further, contending that it is imperative for the music discipline to engage with its new media challenges in order to ensure its contemporary relevance.

Keywords: curriculum leadership, management, academic leadership, university music departments

\section{Introduction}

The notion of leadership in higher education carries many expectations today, 


\section{Chatradari 'Chats' Devroop}

particularly when universities are facing challenges to their legitimacy, from students and the surrounding society (Jansen 2017; Brooks 2017; Habib 2016; Christopherson Gertler \& Gray 2014; Brennan King \& Lebeau 2004). At such times, which are often referred to as crises, dramatic changes of direction and unprecedented transformational measures would need to be addressed, placing new pressures upon university leadership. An expectation of the need for transformational processes and procedures is reinforced by highly publicised student demands, calling for state intervention, which have been directed to the university leadership. There is also a perception in media circles that there is a certain inertia within the university hierarchy generating an expectation on the part of the public, that the 'university problem' could be 'solved' through implementing changes in leadership or by adopting a new direction.

Despite exhaustive research into management and leadership generally, there is a dearth of literature on management and leadership in the arts. I argue here for a new and transformational role for leadership within the contemporary university and in so doing, address some of the current problems outside of a leadership framework, by using a managerial one. This requires optimising the roles for leadership as well as for management within the university and taking cognisance of the dynamics of the arts as a practice. I do this partly on the basis of my experiential learning, as I have been called upon to intervene in the rehabilitation of a university music department which had been placed under proxy administrative and leadership direction for approximately five years, at a time when transformation within university departments and the adaptation of curricula (or recurriculation) were a priority.

This particular music department is one of the pioneering departments in South Africa and has since 1971 been innovative in its diverse curricula (programme) offerings. It remains today one of the few institutions in the country offering a curriculum that encompasses Western Art Music, Jazz and Popular Music, Music Technology, African Music and Dance, as well as Opera and Choral Music. Such diversity in programme offering, at a time when niche focus areas and rationalisation are called for in a market of duplicity, has brought several challenges. One, according to Institutional Intelligence ${ }^{1}$ data, is student migration from diploma to degree programmes where students opt

${ }^{1}$ Previously called the Division of Management Information (2013), now a unit within the Department of Information Communication Services at the University. 
for the practical performance-based or music technology-based modules instead of the theoretical modules. Such migration has a cascading effect on budgetary allocations for more practical teaching and posits challenges in terms of post-graduate progress and ultimately research generation, the latter being a core university activity and key driver in bringing about social change.

Although the university maintained that it was on a trajectory to achieving its transformative goals and targets (Mail \& Guardian 2015; Govinder, Zondo \& Makgoba 2013), with regard to music, certain difficulties appeared in transformation, growth, leadership, staffing, succession planning, curriculum, research production, with an under-preparedness among prospective undergraduates (The Report 2014) ${ }^{2}$. The lack of leadership was identified through the university's audit mechanism as contributing to the challenges that beset the music discipline (The Report 2014: 4). In the context of this data it still remains unclear whether past leadership within the discipline could have contributed to these challenges. In partial response to the university's management and audit findings, the music staff maintained that 'they [management] do not understand us [discipline]'; 'they do not know how music works'; '[management] operates in its mode'; '[management] makes decisions in a way that is completely disconnected from the teaching staff. Management has unfortunately [taken the view] that academics are an impediment to the institution rather than key to it' (The Report 2014). Such claims went so far as to question the university management on the future of the discipline in the face of national resource cuts and new higher education requirements (e.g. staff requiring doctoral degrees, increased teaching workloads, focus on higher research productivity, etc.). This crisis in music is best seen against the context of that of the university and its leadership.

\section{Leadership in the Contemporary South African University: Learning from Others and through Personal Experience}

In the face of growing student dissatisfaction, increasing government scepticism concerning the administration of government subsidies, and a public questioning of the value of tertiary education and its ability to address the problem of youth unemployment, every hierarchical university would feel

${ }^{2}$ The source of this report has been deliberately omitted in order to protect the anonymity of the institution. It is here just referred to as 'The Report'. 


\section{Chatradari 'Chats' Devroop}

that its core values, the fabric of its rule and the basis of its internal solidarity of purpose, were directly under attack. In the US, Arts graduates report that they acquired skills in creative thinking and problem solving $(92 \%)$, research (75\%), project management (68\%), leadership (68\%) and entrepreneurship (27\%) at an Arts school. In addition, 96\% considered the skills they acquired in Art-based programmes as also important to their subsequent work life, whether in or out of the arts (SNAAP 2014: 1). It came as a surprise when Harvard University, one of the leading music departments in the world, decided on a curriculum change citing it as 'an organic move for the times, from both where the field is going generally, but also where we are as faculty' (Suzannah Clark cited in Robin 2017: 1). What this change reveals is adaptability in the transforming nature of the discipline and recognition of the alteration of the demographic profile of its staff.

It could be argued that Harvard University is private and not a public institution, unlike our South African institutions, and thus could risk such a drastic change in discipline focus. It needs to be borne in mind that the stakes are that much higher for a private as opposed to a public institution with such drastic shifts in curriculum. When public universities are hit by a crisis, such as those described by Jansen (2017), they go 'cap in hand' to government for an intervention. In the music scholarship world, Harvard University has remained one of the foremost universities and impacts on research at other universities globally, especially those encountering indigeneity as in South Africa.

Prior to taking up the academic leadership position at the university (2016), I served in academic and administrative capacities (lecturer, academic leader and director) at five other national universities during a time that witnessed South Africa's transition to democracy. This period was also accompanied by the rise in student protests, which Jansen (2017) indicates predates the 2015 events at historically disadvantaged universities and universities of technology. Thus, the challenges facing higher education in the 'new' democracy (post-1994), in terms of its transformation imperatives, are familiar to me. In Badat's (2007: 5) words, they included the definition of the purposes and goals of higher education; extensive policy research; policy formulation, adoption, and implementation:

in the areas of governance, funding, academic structure and programmes, and quality assurance; the enactment of new laws and 
regulations; and major restructuring and reconfiguration of the institutional landscape and of institutions.

The calls for transformation and curriculum reform were thus not unique to my university, but mirror similar challenges for all public universities in South Africa. Naturally, the responsibility and direction in meeting the State's calls became the responsibility of university leaders and managers. I contend that universities exist outside of a context in which the pressures of competition and the prevalence of risk determine the splitting of management and leadership into clearly defined functions, contexts in which the hierarchy of public administration private sector management develops strategies and manages risk. Thus, university authorities and systems are not organised to face pressures from their ecosystem, as are decision makers in politics, public administration, the military and the business world. In the university, a grey area persists in which the functions of management and leadership are seldom made explicit. Administrative responsibilities overlap with the assumption of academic roles, and it is not clear whether appointments are justifiable on the basis of scholarly status or past organisational competence. Given these ambiguities and the fact that criteria for selection are often based on precedent or tradition, there is de facto evidence that management and leadership are currently being severely tested. Discrepancies occur with a merger between a university and a non-university institution, with conflicts arising over oftenveiled assumptions about what is a manageable process versus a leadership process requiring innovation. My premise is that pressures upon the university, whether general or within the organisation of a discipline, are occasions for outlining the role of management and leadership. An appropriate form of these evolving within the often highly specific problems of the university can emerge if we cultivate more of an historical case study, a comparative and an organisational sociological approach, instead of reaching out, during crises in the worlds of public governance or capitalist crisis management, for answers.

For a closer examination of sociological terminology, providing the language with which we may identify some of the hidden processes implicit in social interaction, reference to Margaret Archer's discussion of the interaction between structure and agency provides a useful tool. Archer sees structure as 'those inherited conditions which may be difficult for the individual or the group to alter' (McAnulla 2002: 286). Agency then refers to the individual or the group's desire to influence and mould circumstances providing for a better 


\section{Chatradari 'Chats' Devroop}

and more harmonious contemporary interaction. The dialectic between these two is also affected by culture and this is pertinent for our example, for in the university context culture is actively studied and passed onto the younger generation. According to Archer, both structure and culture function via three processes: conditioning within an inherited social context, subsequent interaction between groups and individuals who may challenge the status quo, and lastly, 'structural' or 'cultural elaboration' or 'reproduction' (McAnulla 2002: 288). This process in which ideas are negotiated and either transformed or reinforced in the course of time, is defined by Archer as a being either a 'morphogenetic' interaction, when transformation takes place, or when the result is merely the reinforcing of existing norms and structures, 'morphostatic' (McAnulla 2002: 287). In any leadership context, agency is either enabled or constrained by the institutional structures in place. In the South African University, this dynamic is further complicated by the complexities which have emerged from a political legacy of inequality and exclusion. The assumption of the responsibilities associated with leadership should take cognizance of this implicit dialectic between structure and agency. Archer's process of morphogenesis, in the context of South Africa which has undergone massive programmes of social engineering, is an important tool in mapping possibilities for transformation within an institutional context.

The debates around leadership and management are not new, nor restricted to universities. Even in the early 1970s, Stogdill (1974: 259) was to claim that there are 'almost as many definitions of leadership as there are persons who have attempted to define the concept'. Using his claim as a departure, I accept that leadership is subjective and is about the ability of an individual(s) to lead in a manner which inspires others to follow (Northhouse 2004). This requires one (the leader) to facilitate decision making, inspire lateral thinking, positive motivation and a strong work ethic within a group, and to implement decisions made by the group. Kotter (2013: webpage) further adds that it is about 'taking an organization into the future, finding opportunities ... and successfully exploiting those opportunities'.

Management, like leadership, is complex to define in that scholars differ with regard to this role based on the differing perspectives of their fields. Economists see it as a resource, some a system of authority (bureaucrats), while others see it as the élite in society (sociologists). There is, however, agreement that the role of a manager is for 'supervising the use of an organization's resources to meet its goals' and that such goals are achieved through 'planning, 
organizing, leading and controlling' (Jones \& George 2003: 30). Kotter (2013) asserts that management and leadership are distinct yet complementary systems. Given these standpoints, I subscribe to the view of Bennis and Nanus (2007: 12), that 'managers do things correctly, while leaders do the correct thing'.

Jansen's As by Fire: The End of the South African University (2017) details the pressure on vice-chancellors to meet student demands of greater accessibility to universities while at the same time facing a declining government subsidy, from 70\% in 1994 to 35\% in 2014 (2017: 28-34). It is evident that a complete reconceptualization of the role of the university in our society and in our cities, is essential if these centres of higher learning are going to be able to respond to the rapidly rising youth demographic and the demand for innovation in all sectors. While it is not that easy to manipulate the organisational structure of the university as a whole, Albert van Jaarsveld, Vice-Chancellor of the University of KwaZulu-Natal has said (2017) that the spatial and working relationship between a university and the city which hosts it, could affect positively its ability to offer real benefit to a city's youth and have real traction in growing the knowledge-base of that city. Van Jaarsveld (2017: 74) states:

We need to open up the campuses to the city. I feel that people who believe that they can adopt the 'Fortress Approach', and still maintain their integrity in the long term, are lacking in foresight. Our university feels strongly that we need to develop the entire community and contribute to the upliftment of this institution, as a consequence of this initiative. Nothing can be achieved by isolating the university from the community as a whole.

It is only in partnership that the university can steer and guide the direction people are taking in a way that will simultaneously ensure that we become the kind of university we would like to be (Devroop \& Theron 2017).

What is clear from both Jansen (2017) and van Jaarsveld (2017) and others, is that the higher education landscape in South Africa is being reshaped. Thus, a call for introspection will be required at all levels of the university and its role in society will require revisiting. Clearly, the student dissatisfaction is seen as an attack on the higher learning institution in its entirety, with its associated traditions and values. South African universities founded during a 


\section{Chatradari 'Chats' Devroop}

colonial era bear a perceived stigma and are criticised as being irrelevant to contemporary society. An uneasy culture of criticism and complaint, directed at the élite strata of the university, has emerged. Interestingly, the challenges to South African universities are not unique: in the United States the Black Lives Matter movement in 2015 saw a call 'about dismantling white supremacy... about decolonisation' (Attiah 2015: webpage).

Given Musselin's (2006: 16) claim that universities are 'unique organizations by virtue of their research and teaching activities', it would be central to the discussion on leadership to examine this uniqueness with a view to establishing how the mobility within such an institution occurs, and gives rise to its leaders.

Academic departments at universities recruit leaders and managers from within their (disciplinary) ranks, most of whom have only experienced life in academia with little knowledge of how leadership functions outside of their sector (Jansen 2017). A similar argument can be made about academics who have little sector-based knowledge about their field. Beckman (2010) in his provocatively titled, Disciplining the Arts: Teaching Entrepreneurship in Context, adds that a challenge lies in the teaching of entrepreneurship to artists whilst simultaneously being flexible and creative. It therefore comes as little surprise that businessman and past trustee of the University of Massachusetts, Carlin (2003: 168), states that he has never 'observed anything as unfocussed or mismanaged as higher education'. Macfarlane (2011: 57), however, goes on to argue that 'new managerialism and performative expectations are reshaping the role of the professoriate, and that institutions need to do more to develop their leadership capacity'. Often these scholars' 'academic prowess, largely relating to research capability' (Yielder \& Codling 2004: 315), or national standing (e.g. National Research Foundation [NRF] rating) is a key factor in 'qualifying' such individuals for favourable upward mobility - often towards the professoriate and even to managerial positions within the university. The standard criteria required for promotion generally revolves around three core areas: teaching and learning, research and community service (with the latter receiving the least weighting). Qualifications in management and leadership or requisite experience in sectors that place a premium on such abilities are seldom required. Experience, which is often listed as a requirement, becomes challenging, in that the system is a hierarchical one - implying that experience can often only be acquired at the expected level once one is promoted (or migrates between institutions). In the case of academic mobility, this is less 
problematic: garnering managerial and leadership experience is only possible through a lateral movement in the other managerial or administrative positions.

\section{Leadership in Music Departments}

Music departments in South Africa have historically operated along the lines of a pseudo conservatory-university model and this posed challenges of its own within the overall structure of the university. These departments are not exclusively theoretical but make creative contributions (performances, compositions, arrangements, productions, and the like) to the sector, community and society. It is this creative role that presents a problem for the university and its management.

Based as it is on the normative curriculum and examination against its background of explicit norms, the university music department is forced to foreground those aspects of music in society that best fit exposition and assessment around norms. The division of labour in western music culture into performing and composing was adequately reproduced by mapping it into the two great divisions of teaching and learning in the conservatory. The relation between music's production by inscription (notation) and its reproduction by playing (performance), could not become a problem in a conservatory.

Once the university undertook to restate the conservatory model as a degree programme, the once combined aspects of composing split into normative accounts of harmony, counterpoint, notation and stylistics with each split into a historical and theoretical exposition. The relation of these normative paraphrases to composition often becomes opaque. Composition is the overwhelming norm of all western performance. It is therefore difficult for universities to insert relevant normative disciplines and sub-disciplines between performance and its dominant norms. Performance thus languishes in an eclectic realm of singularities, anecdotes, precedents and ad hoc explanations within the university. Its actual norm, i.e. what it is a performance of, is not explicable in the curriculated world of the university. Composition appears here only in the refracted form of harmony, theory, counterpoint and so on. The recent eclectic interest in historicist and formalist models borrowed from philosophy, historiography, anthropology, linguistics, cognitive science, hermeneutics, culturalist semiotics and critical social theories are so many attempts to restore the unity of composition and relate it once more to 


\section{Chatradari 'Chats' Devroop}

performance but with the proviso that each element of this restoration of the conservatory status quo, remains normative and hence criticisable and examinable. Thus, the nature and ontology of the discipline itself presents a challenge within the broader university, raising the spectre once again of the tensions between the formal, canonical university curriculum and its practice, and the esoteric world of the arts, as well as the inadequacy of leadership to navigate these spaces.

Staff employed in South African music departments would have attained academic mobility largely through their teaching and published research, while their creative contributions up until 2016 (DHET 2017) would have remained officially 'unrecognized' by the higher education sector. Although certain universities (University of Cape Town, University of KwaZulu-Natal) did have internal recognition mechanisms for creative contributions, such contributions were seldom measured as being on par with their published research colleagues' outputs. This disparity between academic and creative outputs brought about a tension within music departments, and even today remains contentious (Akuno et al. 2017; Whitney 2016) when applied to promotion criteria to the professoriate. The attainment of the full professoriate in music via creative contribution was perceived by staff as being 'more challenging' than that of the path for music researchers. Thus, several of those who went on to become 'heads' of music departments would have attained a doctoral qualification that required a significant written (theoretical) component. Over and above this 'disparity', the challenge for both the academically and creatively driven staff, still centres around their expertise and ability in areas of leadership and management: few have acquired experience or qualifications which enable curriculum leadership in the present context.

Given their history, South African university music departments remain largely colonial in terms of their admission criteria (often with a 'graded' pre-requisite aligned to external music examination bodies such as UNISA, Trinity Guildhall, Associated Board of the Royal School of Music, Rock School); predominantly western (art) in their music curriculum or in recent times, Jazz focus; staffing which does not mirror the national demographic; projected career paths for graduates into sectors that are in decline (Orchestras, Opera, a western art-styled concerting) and catering for the cultural music interests of a minority. This system perpetuates an endless cycle of student-graduate-music teacher-university lecturer, with little impact on the music sector or engagement with the music industry at large. Even the 
national Music competitions (SAMRO, UNISA, Hubert van der Spuy, Philip Moore, ATKV) which some institutions use as a barometer for their music performance 'standards', reinforce the western art and jazz music stereotypes. African music which is 'under-represented in university music curricula worldwide... even in Africa itself ... remain unaddressed' (Ligeti 2017). With diminishing employment prospects for students who are being prepared in a Kittlerian (2004) media system (the university), and in a discipline rooted in yet another media system (the book culture), the music discipline, especially its curriculum has been perceived as slowly moving from survival mode towards a state of 'crisis'. In picking up the gauntlet to transform curriculum, I have questioned whether this is a function of leadership.

\section{Music: Searching for Legitimacy in Contested Spaces}

When universities are pressured to demonstrate their relevance to their stakeholders they usually do so by citing a Science, Technology, Engineering and Mathematics (STEM) justification on the assumption that contemporary societies have a constant need for reliable, applicable knowledge and the technology generating intellectual property that this transacts (Rothwell \& Kulkarni 2015). Contributions of the human and social sciences (such as music) are seldom emphasized (Preston 2015; Grafton \& Grossman 2013; Sinclair 2012). Scholars (Small 2016; Collini 2012; Nussbaum 2012) have argued much against the undervaluing of the humanities. Collini on British Higher Education (Times Higher Education 2013: webpage) goes as far as challenging economic arguments about the humanities, saying facetiously: '...if you make a quick killing in currency trading, then you obviously make more of a contribution than if you teach a child to read'. Thus, with the current STEM university focus, a larger contingent of these academics take up leadership roles and become the voice of the majority. With this emerges university metrics and curricula that favour STEM disciplines. Music and other arts-based disciplines are often at the mercy of decisions made by non-arts personnel, with little empathy for the dilemmas and challenges we face. University leadership has in fact failed to delve beneath the surface.

For music, the life force inherent within it cannot be reduced to a merely economic directive. It evades all academic restraints and is truly democratic, being accessible to all: Elvis Presley, Justin Bieber, Arnold 


\section{Chatradari 'Chats' Devroop}

Schoenberg, Iannis Xenakis, Louis Armstrong, Whitney Houston, Rihanna, Nicky Minaj, are proof of its high degree of autonomy, and that music is a selfexplicative medium. The idea of devising a curriculum or appropriate qualification for this list of musicians, would seem inconceivable. The existing formulaic approach to the university curriculum rooted in an elitist model designed around the orchestral and performance traditions of western Europe and in recent times Jazz of the United States has to be revisited in that the current university curriculum, particularly in South Africa renders itself out of touch with the broader community. In addition, those activities and resources a university does allocate to music in a formal curriculum and with a definite qualification, fall uneasily across the sciences, engineering, technology and the humanities, making the cohesion of a curriculum (and its reform) or the validity of a qualification (as proof of having assembled some type of specific competence in music), even more problematic.

To illustrate further the constraints of formulaic curriculum imposition on music, we need only look at the current eclectic spectrum. Who can dispute that vernacular music has thrived along with Pop in the form of Punk and Reggae, Glam rock and Rock Opera? The demand for complex film scores has burgeoned, the transition to digital media was profitably met by re-recording the standard repertory, the American Hip Hop challenge was buffered and deflected into House, Club and Dance genres, cheaper production software resulted in the new professions of Disc Jockey (DJ), Virtual Jockey (VJ) and the Mix. Even Jazz underwent a rationalisation where Jay Kay and Incognito could occupy different ends of an expanded spectrum and Robbie Williams successfully revived that ballad form of Frank Sinatra. Nobody can claim that the demand for, or the opportunities in music were under threat: it had found a way of diversifying across established media of radio, film and television and elegantly thrived in the second media revolution (Kittler 1999) from analogue to digital form.

Despite all this evidence of a golden age, British academic music departments kept up their consistent tone of complaint as if they were uniquely under threat from neo-liberal funding rationalisation (Dickinson 2013). Music departments complained despite the growing and diversified social and market demands for musical skills extending even to doubling the role of orchestral instrumentalists into orchestra workers plus 'historically informed performance' (HIP) specialists and the transformation of esoteric 'electronic composers' into godfathers of House and Dance-based electronica. 
In the media world, where it has always thrived, music is alive and well yet somehow the university discipline appears to be 'sick' and kept on a 'life support system'. My perplexity grew in leaps and bounds.

Against the backdrop of these perspectives, I entered the fray and viewed my (Academic) leadership role as working around challenges that beset the discipline music in a public institutional setting. As I assessed the battlefield ahead of me, I asked how do other disciplines in arts and humanities cope?

\section{Current Status: Survival Mode}

In accepting the academic leadership role at the university, I was of the view that my task would be primarily one of leadership in the scholarship of teaching and learning and research coupled with chartering the university towards current and future trends that impact the discipline. This role, I envisaged, would also require taking cognizance of the employability of our graduates, its curricular implications and the future of the discipline as music unfolds in society today. Sharp (Jenvey 2012) warns that 'graduates with arts degrees, including music and social science, were 'far more likely to battle'. The 'battle' to which he refers relates to employability due to irrelevant qualifications, changing media contexts, inadequate sector engagement and lack of business acumen.

The challenges I encountered upon taking up the position forced me to question my role and the preconceptions I had about what would be demanded of me, and what the expectations of the university and my staff would be. I classify these challenges into three permeable categories: institutional, departmental and curricular, and expand on their nature below.

Institutional Challenges included:

- Uncertainty around the future of the discipline;

- Funding of the discipline which differs from other university disciplines;

- Lack of adequate technical support for the music studio, concert venues, basic equipment and facilities maintenance;

- Inadequate Staff Performance metrics, and

- Poor engagement with other related institutions for mutual benefit. 


\section{Chatradari 'Chats' Devroop}

Departmental Challenges included:

- Disproportionate demographics in staffing given the diversity of specialisations offered as well as large contract staff dependency;

- Morphostasis due to established habits in thinking and approach to teaching of an existing staff component;

- Recalcitrance, resistance and lack of interest from staff in the larger university project;

- Facilities and fixtures in neglect/disrepair;

- Lack of support by designated university departments in assisting the discipline, and

- Interference and manipulation on the part of external forces (including past staff) in the operations of the department.

Curricular Challenges included:

- Unaccredited entrance qualification offering;

- Duplication of qualifications that yielded the same outcomes;

- A specialisation in a diploma programme in which a core component is absent;

- Honours and Masters theoretical modules that are not articulated by undergraduate practice;

- A high number of module offerings with low student enrolments;

- Anomalies in the module credits (disparate weighting between similar modules); and

- The absence of any entrepreneurship modules.

Applying myself to addressing these challenges included negotiating a legitimate identity and space for music in the university, which is a work in progress.

\section{Swimming Upstream}

In my vision of a way forward, I set a number of new initiatives in place, simultaneously. My aim was to effect what I referred to as a 'new managerialism' (Deem \& Brehony 2005). 
Like a true academic, I conducted research and read. I referred to existing research where a highly significant fusion between managerial perspective and advanced model building and conjecture in social science, as delineated when Pierre Bourdieu (2002) discussed the political economic notion of capital to include other managed capitals of social goods, including culture and learning, status and access to future opportunities.

With regard to the preparation of students for employment, I looked at Boltanski \& Chiapello's (2007) shifts in organisational culture demanded by macro-economic changes, and the university response to recession. In The New Spirit of Capitalism (2007) the 1968-generation, with its radical conceptual innovations, is discussed in terms of its ready-to-adapt framework for reorganising capitalism into its new post-corporate phase based on project economies. These vehement critics of capitalism and its society produced an intellectual and aesthetic legacy with sets of critical and revolutionary attitudes that capitalism later literally transcribed with few modifications into its contemporary managerial theory and value extraction model (Boltanski \& Chiapello 2007).

Based on the work of these pioneers, I then researched how certain university units react to their context particularly when changes in that context affect their understanding of their legitimacy, funding context, financial sustainability and curricular content in such a way as to require them to undertake an unscheduled process of planning.

I then traced the differing fates of two familiar yet key notions in managerial thought, namely, management and leadership, which I began this paper with, in order to develop the characterisation of university music departments in crisis. In critiquing this characterisation, I attempted to refine the types of interaction between the expectations of a music department in its teaching or research duty and participation in management and leadership in the South African university.

Naturally, all of the above entailed much debate, departmentally and university-wide, with resistance and negotiation around perceptions, expectations, goals and delivery. Some of the debates revolved around staff who merged from the 'old' Technikon to the university. They believed that they were employed as teachers and not researchers and resisted any university-wide directive calling on them to engage with research. Other staff felt that their practice needed to be integrated into the performance evaluation mechanism in that this contributed towards university branding. Those staff 


\section{Chatradari 'Chats' Devroop}

who were schooled in a western art tradition felt their curriculum content ought to be privileged because it formed part of a 'global' curriculum norm. These are just a few of the issues that emerged, the results of these and the rest belong in another paper.

\section{The Learning Curve}

What lessons may be learnt from these investigations into the difficulties experienced in this transition in the status of the discipline?

In truth, the real distinctions today between leadership and management may have a limited future, perhaps in general and certainly within the context of music as a discipline. They both belong to an institutional understanding of practices, which applies and understands management or leadership to a stable field where experiences of members and enduring arrangements and decisions provide structure. Such different fields can be expressed as different institutions. The sum of pedagogies - practical, theoretical or reflective - undertaken by universities thus reduces to techniques for inducting 'outsiders' or novices into the many rules, etiquettes, styles, mannerisms, explicit and indirect norms of life within such an institution as a university. When examined from either a managerial or a leadership perspective, the field embodied in the institution is dissected, made explicit and reinstated with different emphases and small, reversible innovations. No amount of management intervention or visionary leadership can turn a university into a church, a courtroom or a stock market.

In the light of these inherent differences it is important to consider that structure and agency are quite distinct from one another and operate in different ways, their relationship can only be understood over time and is dialectical (McAnulla 2002). However, while structure predates agency both have emergent qualities provoked by interaction. While an institutional and departmental framework is inherited, agency still has the ability to affect change in terms of the overall dynamic. What I have found challenging in my role as Academic Leader is that many of the issues forming part of my core mandate have met with pre-existing dynamics of an inherited leadership policy. I did not come to a carte blanche situation but have had to write my thoughts and allow for the interweaving of the vision described in my mandate, with a reticence of attitude, conventions and administrative habits, which Archer terms a pre-existing structure. I have attempted to engage my staff in a 
cooperative agency with the belief that the interaction of potentially conflictual ideas might produce a more synthetic and innovative direction in the transformation process.

But what if a fundamental shift in the understanding of and demand for knowledge and skill drastically changes the requirements of pedagogy? And what if that changed pedagogy exceeds the institutional limits and selfunderstanding of the university?

For music and all other performing arts, the university needs to recognize that there is much that is new, innovative and relevant. These disciplines are directly affected by the emergence of new media, the result of war or profit driven innovation. The problematic relation between film, literature and theatre in the $20^{\text {th }}$ Century is one example but to this could be added the new relations between computation, mathematics, models and experiment, which press science pedagogics into a transdisciplinary form that disturbs the meaning of fact, expertise, evidence and theory as well as pure and applied science and technology into an ambiguous blur.

The relation of music to digital communication makes the medium of its conception, production, storage, distribution and consumption one of the first in history. Few musicians are expert at coding and fewer coders are professional musicians: this ensures that Information Communication Technologies and music in all its aspects are inextricable today and hold the key to one another's potentials, yet neither overlaps nor is reflected in the other. The pedagogy of music and music technology today unfold in universes with no common measure despite music and digital media appearing together inseparably to consumers and music producers alike.

A new management or reorientation of the ideals of leadership in an institution where so many occasions of pedagogy exceed the terms of that institution's field, is essential.

The relation between innovation, medium and skill is still evident today in the music project. This is a value chain built and rebuilt in networks which themselves are temporary, transactional and inaugurated by the unpredictable appearance of new intellectual property, in short, projects are almost the complete inversion of the kinds of knowledge, learning and process able to occur in institutions. Projects are mutations in the field and parameters that underpin learning institutions. They replace education with experiment in overt value chains that are open to redesign as a result of input or criticism from broad and unpredictable sources. These value chains are defined by the 


\section{Chatradari 'Chats' Devroop}

project and are not a pre-existent field that can be used to analyse or critique their associated project. Boltanski and Chiapello (2007) have used this insight into what Bourdieu (2002) had analysed as the relations between field, habitus, various forms of capital and their institutional or disciplinary expression to suggest that at present, a new, projective form of this set of relationships is emerging.

\section{Concluding Comments}

I argue that a new pedagogy is emerging, again, that universities need to recognize, resource and enable, and departmental heads and staff need to enact. The disintegration of production and publishing empires, distribution systems and of traditional rituals favouring live music events along with other shifts in music intermediations has led to a permanent rethinking of the composer, producer, performer and technician roles. New genres of music have emerged through this new dispensation, as have lasting impacts upon old genres separation from media of production and distribution. The pedagogy of this fully overhauled music-world hardly exists: its inception in innovation and the lifelong learning essential to a skills market created by competing demands of projects and new, often hybrid roles within value chains means that a finite pedagogy and a definable competence no longer exists. It needs to be engendered, actively.

Understanding the projective city and sketching the rudiments of its management and possible forms of initiative must be the task of every institutional music pedagogy.

Managing the music department out of its institutional shell and towards the project economy without dissolving its usefulness as a site of learning, is thus today's challenge. It requires insight into risk and unprecedented innovation in a new managerialism which brings in leadership more effectively, or perhaps, the ability to successfully de-risk and to innovate in ways that meet the reforms of the times we now live in. In short, the academy has some catching up to do.

\section{References}

Akuno, E.A., D.O. Ondieki, P.L. Barasa, S.P. Otieno, C.M. Wamuyu \& M.O. 
Amateshe 2017. Higher Education Leadership and Governance in the Development of the Creative and Cultural Industries in Kenya. Dakar: Council for the Development of Social Sciences Research in Africa.

Attiah, K. 2015. Woodrow Wilson and Cecil Rhodes Must Fall. Available at: https://www.washingtonpost.com/blogs/post-

partisan/wp/2015/11/25/woodrow-wilson-and-cecil-rhodes-mustfall/?utm term=.636cd38176f9. (Accessed on 01 August 2017.)

Badat, S. 2007. Higher Education Transformation in South African Post 1994.

Towards a Critical Assessment. Johannesburg: Centre for Education and Policy Development.

Beckman, G.D. 2010. Disciplining the Arts: Teaching Entrepreneurship in Context. Lanham, MD: Rownam and Littlefield.

Bennis, W.G. \& B. Nanus 2007. Leaders: Strategies for Taking Charge. New York, NY: HarperCollins.

Boltanski, L. \& E. Chiapello 2007. The New Spirit of Capitalism. London: Verso.

Bourdieu, P. 2002. The Forms of Capital. In Biggart, N.W. (ed.): Readings in Economic Sociology. Malden, MA: Blackwell Publishers.

https://doi.org/10.1002/9780470755679.ch15

Brennan, J., R. King \& Y. Lebeau 2004. The Role of Universities in the Transformation of Societies. London: Association of Commonwealth Universities.

Brooks, R. (ed.). 2017. Student Politics and Protest: International Perspectives. London: Routledge.

Carlin, J.F. 2003. Restoring Sanity to an Academic World Gone Mad. In DeCew, J.W (ed.): Unionisation in the Academy. Lanham, MD: Rowman \& Littlefield Publishers.

Christopherson, S., M. Gertler \& M. Gray 2014. Universities in Crisis. Cambridge Journal of Regions, Economy and Society 7,2: 209 - 215.

https://doi.org/10.1093/cjres/rsu006

Collini, S. 2012. What Are Universities For? London: Penguin.

Deem, R. \& K.J. Brehony 2005. Management as Ideology: The Case of 'New

Managerialism' in Higher Education. Oxford Review of Education 31,2:

$217-235$.

https://doi.org/10.1080/03054980500117827

Devroop, C. \& P. Theron 2017. Durban. From Playing the Host to Projecting Ideas. In Zamboni, A. \& J.P. de la Porte (eds.): Domus. Milan: Editoriale 
Domus S.p.A. July-August, 1015: 67 - 76.

Dickinson, P. (ed.). 2013. Music Education in Crisis: The Bernarr Rainbow

Lectures and Other Assessments. Suffolk: Boydell and Brewer.

DHET (Department of Higher Education and Training) 2017. Policy on

Evaluation of Creative Outputs and Innovations Produced by South

African Public Higher Education Institutions 2017. Pretoria: Department

of Higher Education and Training, No. 40819: 4 - 27.

Govinder, K.S., N.P. Zondo \& W.M. Makgoba 2013. A New Look at Demographic Transformation for Universities in South Africa. South African Journal of Science. Available at:

http://www.scielo.org.za/scielo.php?script=sci_arttext\&pid=S0038-

23532013000600014. (Accessed on 12 February 2016.)

Grafton, A.T. \& J. Grossman 2013. The Humanities in Dubious Battle.

Available at:

http://www.chronicle.com/article/The-Humanities-in-Dubious/140047/.

(Accessed on 19 March 2017.)

Habib, A. 2016. Reimagining the South African University and Critically Analysing the Struggle for its Realisation. Available at:

https://www.wits.ac.za/news/latest-news/in-their-own-words/2016/2016-

01/reimagining-the-south-african-university-and-critically-analysing-

the-struggle-for-its-realisation.html (Accessed on 17 July 2016.)

Jansen, J. 2017. As By Fire. The End of the South African University. Cape Town: Tafelberg.

Jenvey, N. 2012. Graduate Unemployment in a Skills-short Economy Bedevils

Growth. Available at:

http://www.universityworldnews.com/article.php?story=2012112214001 9904. (Accessed on 01 June 2017.)

Jones, G.R. \& J.M. George 2003. Contemporary Management. New York, NY: McGraw-Hill.

Kittler, F.A. 2004. Universities: Wet, Hard, Soft and Harder. Critical Inquiry $31,1: 244-255$.

https://doi.org/10.1086/427310

Kittler, F.A. 1999. Gramophone, Film, Typewriter. Winthrop-Young, G. \& M. Wutz (trans.). Stanford, CA: Stanford University Press.

Kotter, J.P. 2013. Management is (Still) Not Leadership. Available at:

https://hbr.org/2013/01/management-is-still-not-leadership. (Accessed on 01 June 2017.) 
Ligeti, L. 2017. An African-Based Avant-Garde: Training for Art-Music Composers Based on Concepts from African Traditions. Paper presented at the $10^{\text {th }}$ Pan African Society for Musical Arts Education (PASME) Conference, Mbabane, Swaziland. 29 June - 02 July 2017.

Macfarlane, B. 2011. Professors as Intellectual Leaders: Formation, Identity and Role. Studies in Higher Education 36,1:57 - 73.

https://doi.org/10.1080/03075070903443734

Mail \& Guardian 2015. Transformation: Part of Everyday Business at UKZN.

Available at: https://mg.co.za/article/2015-09-04-00-transformation-partof-everyday-business-at-ukzn. (Accessed on 14 February 2017.)

McAnulla, S. 2002. Structure and Agency. In Marsh D. \& G. Stoker (eds.): Theory and Methods in Political Science. $2^{\text {nd }}$ Edition. New York: Palgrave Macmillan.

https://doi.org/10.1007/978-0-230-62889-2_14

Musselin, C. 2006. Are Universities Specific Organisations? In Krücken, G., A. Kosmützky \& M. Torka (eds.). Towards a Multiversity? Universities between Global Trends and National Traditions. Bielefeld: Transcript Verlag.

https://doi.org/10.14361/9783839404683-004

Northouse, P.G. 2004. Leadership: Theory and Practice. London: Sage Publications.

Nussbaum, M.C. 2012. Not for Profit: Why Democracy Needs the Humanities. Princeton, NJ: Princeton University Press.

Preston, A. 2015. The War against Humanities at Britain's Universities. Available at: https://www.theguardian.com/education/2015/mar/29/waragainst-humanities-at-britains-universities. (Accessed on $16 \mathrm{March}$ 2017.)

Robin, W. 2017. What Controversial Changes at Harvard Mean for Music in the University. Available at: http://thelogjournal.com/2017/04/25/whatcontroversial-changes-at-harvard-means-for-music-in-the-university/ (Accessed on 12 July 2017.)

Rothwell, J. \& S. Kulkarni 2015. Beyond College Rankings. A Value-Added Approach to Assessing Two- and Four-Year School. Available at: https://www.brookings.edu/wp-

content/uploads/2015/04/BMPP CollegeValueAdded.pdf. (Accessed on 16 March 2017.)

Sinclair, S. 2012. Confronting the Criticisms: A Survey of Attacks on the 
Humanities. Available at: http://4humanities.org/2012/10/confrontingthe-criticisms/ (Accessed on 19 March 2017.)

Small, H.H. 2016. The Value of the Humanities. Oxford: Oxford University Press.

SNAAP (Strategic National Arts Alumni Project) 2014. Tracking the Lives and Careers of Arts Graduates in America. Available at:

http://snaap.indiana.edu/snaapshot/\#disciplines (Accessed on 08 June 2018.)

Stogdill, R.M. 1974. Handbook of Leadership: A Survey of Theory and Research. New York, NY: Free Press.

The Report 2014. University Report on External Review of the Music Discipline in the School of Arts. September 2014. (Unpublished Report.) Times Higher Education. 2013. Collini Lambasts Oxford's Economic Defence of Humanities. Available at:

https://www.timeshighereducation.com/news/collini-lambasts-oxfordseconomic-defence-of-humanities/2008392.article. (Accessed on 30 July 2017.)

Whitney, K. 2016. Following Performance across the Research Frontier. In

Doğantan-Dack, M. (ed.): Artistic Practice as Research in Music: Theory,

Criticism, Practice. Oxford: Routledge.

Yielder, J. \& A. Codling 2004. Management and Leadership in the Contemporary University. Journal of Higher Education Policy and Management 26,3:315 - 328.

https://doi.org/10.1080/1360080042000290177

Chatradari 'Chats' Devroop School of Arts College of Humanities University of KwaZulu-Natal devroopc@ukzn.ac.za 